\title{
Co-liquefaction of Coal and Used Tire in Supercritical Water
}

\author{
Kwanruthai Onsri ${ }^{1}$, Pattarapan Prasassarakich ${ }^{1,2}$, Somkiat Ngamprasertsith ${ }^{1,2^{*}}$ \\ ${ }^{1}$ Fuels Research Center, Department of Chemical Technology, Faculty of Science, \\ Chulalongkorn University, Bangkok, Thailand \\ ${ }^{2}$ Center for Petroleum, Petrochemicals and Advance Materials, Chulalongkorn University, \\ Bangkok, Thailand \\ E-mail: somkiat.n@chula.ac.th \\ Received December 19, 2009; revised January 8, 2010; accepted March 3, 2010
}

\begin{abstract}
The co-liquefaction of lignite coal and used tire was performed in a $250-\mathrm{ml}$ batch reactor, in supercritical water under a nitrogen atmosphere to investigate the effects of temperature $\left(380-440^{\circ} \mathrm{C}\right)$, water/feedstock ratio (4/1-10/1 (wt./wt.)) and the \% used tire content in the feedstock (0-100 wt.\%) on the conversion efficiency, liquid yield and oil composition attained. The maximum conversion and oil yield were 67 and 50\%, respectively, obtained at $400^{\circ} \mathrm{C}$ at $1 \mathrm{~min}$, with water/feedstock ratio of $10 / 1$ and $80 \%$ used tire content. The distillation characteristics of the oil products, analyzed by simulated distillation gas chromatography, revealed that the oil composition depended significantly on the reaction temperature. The co-liquefaction of coal and used tire yielded a synergistically increased level of oil production. Moreover, the total conversion level obtained with co-liquefaction alone was almost equal to those obtained in the presence of either $\mathrm{Fe}_{2} \mathrm{O}_{3}$ or NiMo as catalysts, under the same conditions. Therefore, supercritical water is a good medium for the dissolution of the volatile matter from a coal and used tire matrix.
\end{abstract}

Keywords: Co-liquefaction, Coal, Used Tire, Supercritical Water

\section{Introduction}

In recent years, the growth in tire consumption has continued to expand concomitantly leading to the problem of the disposal of an ever increasing number of essentially non-biodegredable but flammable spent scrap tires without causing environmental pollution (including combustion). With in excess of 3.0 million tons per year of waste tires being produced in just the USA and Japan alone [1], this has become a major challenge. Indeed, currently perhaps only $60-70 \%$ of all used tires are recycled, and evens this requires the use of environmentally and economically costly processes including the use of solvents like n-hexane, toluene and tetralin [2,3]. Used tires are comprised of vulcanized natural and synthetic rubbers, zinc, sulfur and carbon black and, as such, contain polymeric aromatic structures that are somewhat similar to those in coal. Hence, the well-developed techniques used in coal utilization should theoretically be applicable to the pyrolytic destruction of waste tires and there has been an increasing amount of attention paid to the co-utiliza- tion of coal and waste tires. Indeed, given that coal liquefaction is enhanced by the addition of crude oil [4] which is a source of rubber constituents in tires, the coliquefaction of coal and used tires is of obvious interest.

A number of different concepts for the degradation of spent tires in the presence of coal have hitherto contributed to the background knowledge. The processing of used tire and/or coal have been subjected to thermal pyrolysis and supercritical extraction using toluene, helium, nitrogen and water. Mastral et al. [5] investigated subbituminous coal-tire hydroprocessing and reported that oil formation and total solid conversion reached $45 \%$ and $70 \%$, respectively, at a reaction temperature of $400^{\circ} \mathrm{C}$, with a coal: tire ratio of 0.5 and $10 \mathrm{MPa}$ initial hydrogen pressure. Moreover, the presence of rubber tire had a positive effect as an additive for coal hydropyrolysis and this was more relevant when tire feeds were coprocessed. In a similar vein, synergistic effects including increased total conversion levels and the yields of oil and asphaltene were attained during the simultaneous hydrogenolysis of coal and tire were reported [2-9]. Joung et al. [3] 
studied the thermolysis of scrap tire using supercritical toluene $\left(\mathrm{T}>318.6^{\circ} \mathrm{C}, \mathrm{P}>4.06 \mathrm{MPa}\right)$ and cyclohexane under a nitrogen atmosphere and reported that the conversion level reached $100 \%$ for toluene once the critical state of toluene was reached $\left(350^{\circ} \mathrm{C}\right)$. Indeed, temperature was far more important than other variables including pressure for the complete dissolution of tire materials. However, moving away from organic solvents as the hydrogen donor to the cheaper and environmentally friendlier water, the potential of supercritical water (SCW) was first evaluated by Funazukuri et al. [10] who reported that $\mathrm{SCW}$ was almost as effective as toluene for tire liquefaction, attaining around $57 \%$ of tire solids to oils. Finally, Park and Gloyna [11] reported that the liquefaction of used rubber tire by using SCW under a helium atmosphere attained a conversion and liquid yield level of $89 \%$ and $68 \%$, respectively.

The type of solvent used is likely to play a key role as it acts as a medium to aid in the transport of hydrogen, as a heat transfer medium reactant (including hydrogen donor) and dissolution media to transport rubber and especially coal liquefaction products out of the matrix. However, previous research works have reported that SCW $\left(\mathrm{T}>374^{\circ} \mathrm{C}, \mathrm{P}>22 \mathrm{MPa}\right.$ ) is an alternative approach for the conversion of coal and tire into liquid products $[10$, 11]. The use of SCW as the reaction solvent can change the reaction rate, equilibrium, and principal reaction pathway, specifically around the critical point, because of the significant variation in water properties [12]. Thus $\mathrm{SCW}$ can dissolve hydrocarbons whose dielectric constant is widely variable. In addition, the use of SCW as opposed to organic solvents serves to both reduce the cost and avoid the problems associated with the removal of the solvent from the products. The separation of the liquid extracted from coal and organic solvents typically requires a tedious procedure to achieve any degree of completion and product purity, and is both economically and environmentally costly [13].

In this study, coal and used tire co-liquefaction were conducted in $\mathrm{SCW}$ under a $\mathrm{N}_{2}$ atmosphere and the effects of the reaction temperature, the water/feedstock ratio, \% used tire content in feedstock and the presence of catalysts on the co-liquefaction efficiency were investigated and are discussed with reference to the product composition.

\section{Experiment Apparatus and Procedure}

\subsection{Material and Chemicals}

The lignite coal used in this study was obtained from the Mae Moh lignite mine in Lampang province, northern Thailand. The used tire was obtained from Union Pattanakij Ltd. They were grounded, sieved (particle size is in range of $250-850$ micron), dried at $110^{\circ} \mathrm{C}$ overnight and then kept in the desiccator. The proximate and ultimate
Table 1. Proximate and ultimate analysis of coal and used tire.

\begin{tabular}{ccc}
\hline & Coal & Used tire \\
\hline Proximate analysis $\left(w t . \% d b^{1}\right)$ & & \\
\hline Ash & 21.6 & 3.5 \\
Fixed carbon & 59.4 & 67.8 \\
Volatile matter & 19.1 & 28.7 \\
Moisture (original sample, \%) & 17.7 & 1.1 \\
\hline Ultimate analysis (wt.\% daf ${ }^{2}$ ) & & \\
\hline Carbon & 66.4 & 85.8 \\
Hydrogen & 5.1 & 8.0 \\
Nitrogen & 2.6 & 0.5 \\
Sulfur & 4.6 & 1.5 \\
Oxygen (by difference) & 21.3 & 4.3 \\
H/C atomic ratio & 0.9 & 1.1 \\
Heating value (MJ/kg) & 21.3 & 33.6 \\
\hline
\end{tabular}

${ }^{1} \mathrm{db}=$ dry basis, ${ }^{2}$ daf $=$ dry ash-free basis

analysis of lignite and used tire are presented in Table 1.

Other chemicals were: Tetrahydrofuran (THF) (+ 99.99\%) purchased from Fisher Chemicals, Dichloromethane $\left(\mathrm{CH}_{2} \mathrm{Cl}_{2}\right)$ and Anhydrous sodium sulfate purchased from CARLO ERBA and Carbon disulfide $\left(\mathrm{CS}_{2}\right)$ (99\%) purchased from Merck.

\subsection{Procedure}

The experimental scheme for co-liquefaction of coal and used tire constituent is summarized in Figure $\mathbf{1}$ and schematic of apparatus is shown in Figure 2. The co-liquefaction reactions were carried out in a $250-\mathrm{ml}$ reactor (Parr reactor model 4843). The reactor filled with water under nitrogen atmosphere. The water-filling content (percentage water volume to reactor volume) was $15-17 \%$ which this amount of water caused the pressure approaching 24-25 MPa at the desired temperature (380 $\left.-440^{\circ} \mathrm{C}\right)$. The calculated amounts of coal and used tire were loaded in the reactor at the specific ratio.

The reactor was heated to the desired temperature, above the water critical temperature at a heating rate of $5^{\circ} \mathrm{C} / \mathrm{min}$, and held at this temperature for $1 \mathrm{~min}$. The reactor was then cooled to room temperature and the products transferred by washing into, and extracted with THF, in an ultrasonic bath. After the THF extraction, the product mixture was filtered to separate solid from liquid, and the solid residue was dried for $4 \mathrm{~h}$ in an oven at $110^{\circ} \mathrm{C}$ to remove the residual solvent. The liquid products were separated into both oil and aqueous phases by $\mathrm{CH}_{2} \mathrm{Cl}_{2}$ using a separation funnel. Anhydrous sodium sulfate was added to the isolated oil phase to remove the trace 
amounts of residual water remaining in the oil phase and then evaporated in a vacuum rotary evaporator at $60^{\circ} \mathrm{C}$ and $400 \mathrm{mmHg}$ to remove the $\mathrm{CH}_{2} \mathrm{Cl}_{2}$ and THF solvent residues. The evaporated liquid (oil) was weighed to calculate the liquid yield. The total conversion, liquid and gas yields and solid residue levels were calculated by the following expressions:

$\%$ Conversion $=100[(\mathrm{Wdaf}-\mathrm{WRT}) / \mathrm{Wdaf}]$

$\%$ Liquid yield $=100[\mathrm{Wliq} / \mathrm{Wdaf}]$

$\%$ Solid residue $=100[\mathrm{WRT} / \mathrm{Wdaf}]$

$\%$ Gas yield $=100-\%$ Liquid yield - \% Solid residue where: Wdaf $=$ wt. of dry-ash free coal and used tire mixture, WRT $=$ wt. of dry-ash free residue remaining after THF solvent wash and dry, Wliq = wt. of liquid. All experiments were conducted in duplicate.

\subsection{Product Analysis}

In this study, the raw coal and used tire was analyzed for proximate analysis, total sulfur and determined the heating value by ASTM D2492, D3177 and D2015, respectively. The carbon, hydrogen and oxygen were performed using a CHN analyzer (Leco CHN-2000).

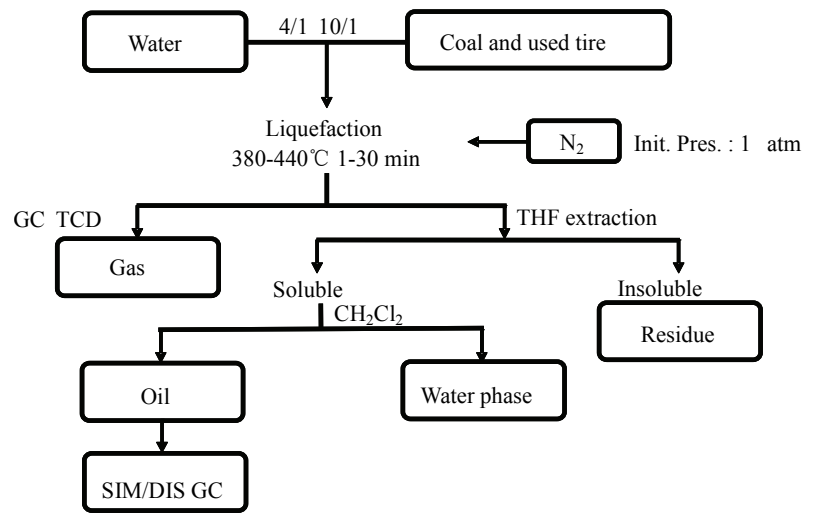

Figure 1. Experimental scheme.

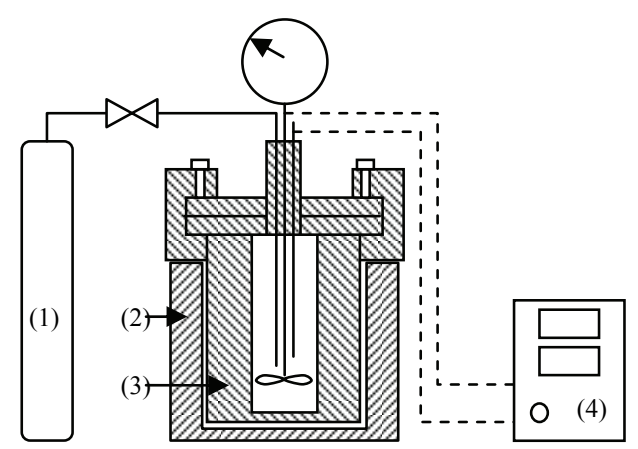

Figure 2. Schematic diagram of the apparatus. (1) $\mathrm{N}_{2}$ gas cylinder. Parr reactor model 4843 consisted of; (2) Heater; (3) 250-ml high temperature and pressure reactor; (4) Temperature and pressure controller.
The liquid product was analyzed by Simulated Distillation Gas Chromatography (SIM/DIS GC, Varian Model CP-3800) according to ASTM D2887. Star Simulated Distillation version 5.5 software was used for data collection and processing. The liquid was dissolved in $1 \%(\mathrm{v} / \mathrm{v}) \mathrm{CS}_{2}$ and a $15 \mathrm{~m} \times 0.25 \mathrm{~mm} \mathrm{Cp-SIL5CB}$ column was used for separation. The oven temperature was raised from 30 to $370^{\circ} \mathrm{C}$ at a constant heating rate of $20^{\circ} \mathrm{C} / \mathrm{min}$. The distillation curve was evaluated to fractions as follows: IBP- $200^{\circ} \mathrm{C}$, gasoline; $200-250^{\circ} \mathrm{C}$, kerosene; 250 $350^{\circ} \mathrm{C}$, light gas oil; $350-370^{\circ} \mathrm{C}$, gas oil; and $370^{\circ} \mathrm{C}-\mathrm{FBP}$, long residue.

The gaseous product was analyzed by Gas Chromatograph with a Thermal Conductivity Detector (GC-TCD, Shimadzu GC-2014). The GC-TCD conditions were as follows: $90^{\circ} \mathrm{C}$ injection temperature; He carrier gas; Porapak Q column and $50^{\circ} \mathrm{C}$ column temperature.

\section{Results and Discussion}

\subsection{Preliminary Study}

In the initial stage of study co-liquefaction of coal and used tire, the factorial design was used to analyze the significant process variables. Three variables such as temperature, water/feedstock ratio (wt./wt.) and used tire content in feedstock (wt.\%) were chosen. Each of the variables was coded at two levels: -1 and +1 as shown in Table 2 and the average $2^{3}(=8)$ experimental results including $\%$ conversion and \% liquid yield of 2 replications were showed in Table 3.

The analysis using the 2-level factorial design method was based on an evaluation of variance ratios. Such comparison helped to determine whether or not significant difference existed among the means of several groups of observation. It was assumed that each group followed a normal distribution and its trend of the response between ranges of studied variables is linear. The F-test (95\% confidence limits) method was used. The calculated results were showed in Table 4. These results showed that only temperature had effect on \% conversion, while all three variables (temperature, Water/feedstock (wt./wt.) ratio and \% used tire in feedstock) had effect on $\%$ liquid yield.

However, the effect of reaction time on the product distribution of the co-liquefaction was not studied, be-

Table 2. Factorial design of experiments.

\begin{tabular}{ccc}
\hline Factor & \multicolumn{2}{c}{ Level } \\
\hline Temperature $\left({ }^{\circ} \mathrm{C}\right), \mathrm{A}$ & -1 & +1 \\
Water/feedstock ratio (wt./wt.), B & 380 & 440 \\
\% Used tire content in feedstock (wt.\%), C & $4 / 1$ & $10 / 1$ \\
\hline
\end{tabular}


Table 3. Experimental results obtained from factorial design for co-liquefaction experiments.

\begin{tabular}{|c|c|c|c|c|c|}
\hline \multirow{3}{*}{$\begin{array}{l}\text { Factorial } \\
\text { Design }^{*}\end{array}$} & \multicolumn{3}{|c|}{ Factor } & \multirow[t]{3}{*}{$\%$ Conversion } & \multirow{3}{*}{$\begin{array}{c}\text { \% Liquid } \\
\text { yield }\end{array}$} \\
\hline & Temperature & Water/feedstock & $\%$ Used tire content & & \\
\hline & $\left({ }^{\circ} \mathrm{C}\right), \mathrm{A}$ & Ratio (wt./wt.), B & in feedstock (wt.\%), C & & \\
\hline (1) & 380 & $4 / 1$ & 20 & 53.9 & 15.0 \\
\hline $\mathrm{a}$ & 440 & $4 / 1$ & 20 & 62.6 & 24.9 \\
\hline $\mathrm{b}$ & 380 & $10 / 1$ & 20 & 56.3 & 25.5 \\
\hline$a b$ & 440 & $10 / 1$ & 20 & 63.4 & 28.6 \\
\hline $\mathrm{c}$ & 380 & $4 / 1$ & 80 & 53.2 & 26.6 \\
\hline ac & 440 & $4 / 1$ & 80 & 62.4 & 36.0 \\
\hline $\mathrm{bc}$ & 380 & $10 / 1$ & 80 & 60.0 & 40.2 \\
\hline$a b c$ & 440 & $10 / 1$ & 80 & 68.2 & 41.6 \\
\hline
\end{tabular}

* Reaction conditions are denoted according to statistical nomenclature;

e.g. ab represents high levels of factors A and B and low levels of C and D (see Table 2)

Table 4. Analysis of variance for co-liquefaction experiments. (a) for \% conversion; (b) for \% liquid yield.

\begin{tabular}{ccccc}
\hline $\begin{array}{c}\text { Source of } \\
\text { Variation }\end{array}$ & $\begin{array}{c}\text { Sum of } \\
\text { Square }\end{array}$ & $\begin{array}{c}\text { Degrees of } \\
\text { Freedom }\end{array}$ & $\begin{array}{c}\text { Mean } \\
\text { Square }\end{array}$ & $\mathrm{F}_{0}$ \\
\hline $\mathrm{A}$ & 137.74 & 1 & 137.74 & $37.21^{*}$ \\
$\mathrm{~B}$ & 30.69 & 1 & 30.69 & 8.29 \\
$\mathrm{AB} * *$ & 0.90 & 1 & 0.90 & 0.24 \\
$\mathrm{C}$ & 7.29 & 1 & 7.29 & 1.97 \\
Error & 11.10 & 3 & 3.70 & \\
\hline Total & 187.73 & 7 & & \\
\hline
\end{tabular}

(a)

\begin{tabular}{ccccc}
\hline $\begin{array}{c}\text { Source of } \\
\text { Variation }\end{array}$ & $\begin{array}{c}\text { Sum of } \\
\text { Square }\end{array}$ & $\begin{array}{c}\text { Degrees of } \\
\text { Freedom }\end{array}$ & $\begin{array}{c}\text { Mean } \\
\text { Square }\end{array}$ & $\mathrm{F}_{0}$ \\
\hline A & 70.92 & 1 & 70.92 & $9.13^{*}$ \\
B & 138.83 & 1 & 138.83 & $17.87^{*}$ \\
C & 315.63 & 1 & 315.63 & $40.63^{*}$ \\
Error & 31.07 & 4 & 7.77 & \\
\hline Total & 556.45 & 7 & & \\
\hline
\end{tabular}

(b)

* Significant in F-test with $95 \%$ confidence limits, $\mathrm{F}_{0.05,1,3}=10.13\left(\mathrm{~F}_{0}>\right.$ $\mathrm{F}_{0.05,1,3)}$

* Significant in F-test with $95 \%$ confidence limits, $\mathrm{F}_{0.05,1,4}=7.71\left(\mathrm{~F}_{0}>\right.$ $\mathrm{F}_{0.05,1,4)}$

** Two-factor interaction effects of factors A and B (see Table 2)

cause the results from initial experiments of liquefaction of the used tire, as shown in Figure 3, showed that the reaction time (elapsed time after the temperature reached the desired temperature) did not affect the product distribution. Moreover, the previous studies [14-16] reported that the coal and some polymers including rubber

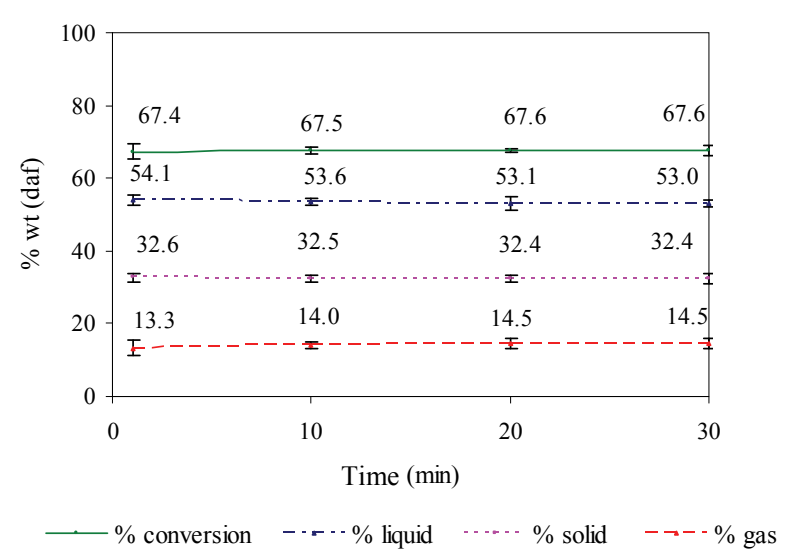

Figure 3. The effect of temperature on the distribution of products for used tire liquefaction. (Temperature $420^{\circ} \mathrm{C}$; water/feedstock ratio of 10/1).

and plastics can be decomposed and give the highest oil yield within $1 \mathrm{~min}$. Thus, we used the reaction time of 1 min for all of co-liquefaction experiments.

\subsection{The Effect of Temperature}

Thermal cracking is the principal reaction in SCW and the effect of temperature on thermal cracking is important. Thermogravimetric analysis curves revealed the weight loss of used tire when pyrolyzed at a constant heating rate of $10^{\circ} \mathrm{C} / \mathrm{min}$ within a temperature range of $25-900^{\circ} \mathrm{C}$ under a nitrogen atmosphere (Figure 4). The decomposition of used tire begins in earnest near $380^{\circ} \mathrm{C}$ and is essentially completely decomposed at $480^{\circ} \mathrm{C}$. Therefore, the chosen temperature range for all subsequent co-liquefaction experiments was $380-440^{\circ} \mathrm{C}$. Figure 5 summarizes the variation in product yield with reaction temperature at a reaction time of $1 \mathrm{~min}$, a water/feed stock ratio of $10 / 1$ and a substrate composition 


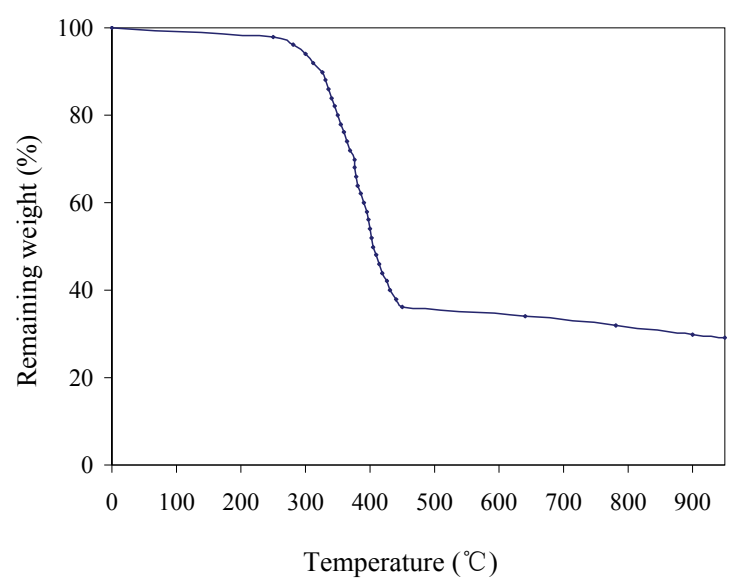

Figure 4. Thermogravimetric analysis curve of used tire.

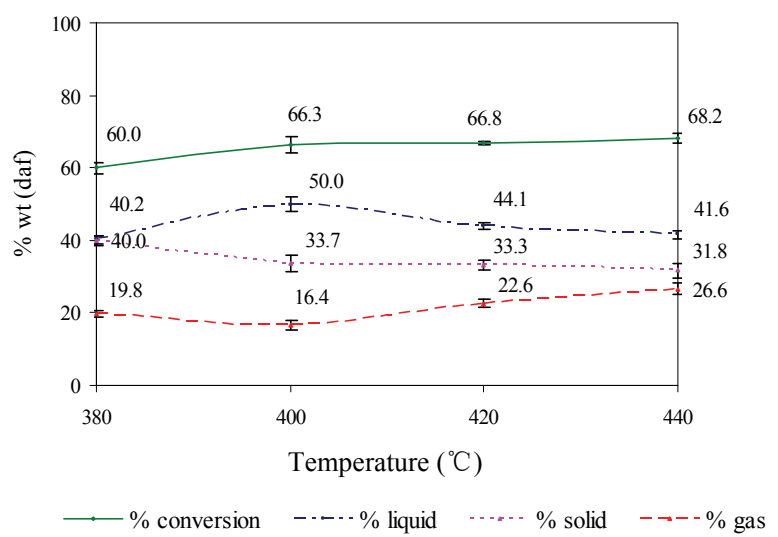

Figure 5. The effect of temperature on the distribution of products for co-liquefaction. (Reaction time $1 \mathrm{~min}$; water/feedstock ratio of $10 / 1 ; 80 \%$ used tire content in feedstock).

of $80 \%$ used tire. The yield of liquid product increased from that obtained at $380^{\circ} \mathrm{C}$ to a maximum level at $400^{\circ} \mathrm{C}$ and thereafter decreased with further temperature increases. At lower temperature, the liquid could be extracted from coal, the used tire was decomposed and then yielded the heavy liquid products. However, with increasing reaction temperatures, the residue yield decreased because of the further thermal decomposition of heavy liquid product and solid residue could be took place and resulted in decreased liquid and residue yields at temperatures above $400^{\circ} \mathrm{C}$ and a concomitant increase in gas yields.

The total conversion level, which increased with temperature rises from 380 to $400^{\circ} \mathrm{C}$, did not significantly change with further temperature increases from 400 to $440^{\circ} \mathrm{C}$, whilst the liquid yield was decreased, presumably via the decomposition of long chained hydrocarbons into gaseous products. Moreover, the total conversion attained at $400^{\circ} \mathrm{C}$ was almost equal to that attained at $440^{\circ} \mathrm{C}$ some 8 min later. Therefore, it can be concluded that the optimum temperature and reaction time was $400^{\circ} \mathrm{C}$ and 1 $\min$.

\subsection{The Effect of Water/Feedstock Ratio}

The effect of varying the water/feedstock ratio on the yield of products attained at $400{ }^{\circ} \mathrm{C}$ with a reaction time of $1 \mathrm{~min}$ and $80 \%$ used tire content is summarized in Figure 6. Whilst the yield of gas remained stable, the liquid oil yield was slightly increased with increasing water content and reached $50 \%$ at the maximum water/feedstock ratio of $10 / 1$ whilst the levels of residual solids were concomitantly decreased. The mechanism of coal pyrolysis starts with SCW diffusing into the coal matrix and acting as a medium for the dissolution of coal fragments. At the supercritical state, the static dielectric constant of water decreases dramatically, leading to the miscibility of nonpolar organic compound with SCW [15, 17,18]. The products from coal pyrolysis can dissolve and disperse in the SCW and, as a result, the conversion of coal is enhanced in the presence of water.

Moreover, the water gas shift reaction $\left(\mathrm{CO}+\mathrm{H}_{2} \mathrm{O} \rightarrow\right.$ $\mathrm{CO}_{2}+\mathrm{H}_{2}$ ) occurs as a side reaction during coal and used tire conversion in $\mathrm{SCW}$. The $\mathrm{CO}$ produced from partial-oxidation of oxygen-contained functional groups of coal and then reacts with water in SCW to produce carbon dioxide and hydrogen. The appearance of carbon dioxide in the gas product was shown in Figure 7. Increasing the water/feedstock ratio in partial-oxidation of coal in SCW causes the equilibrium to favor carbon dioxide and hydrogen production leading to higher rates and levels of reactive intermediate hydrogen production, which is the actual hydrogenation agent [12]. The generated hydrogen reacts with free radicals produced from the thermal cracking of coal and used tires, and so liquid products are increased.

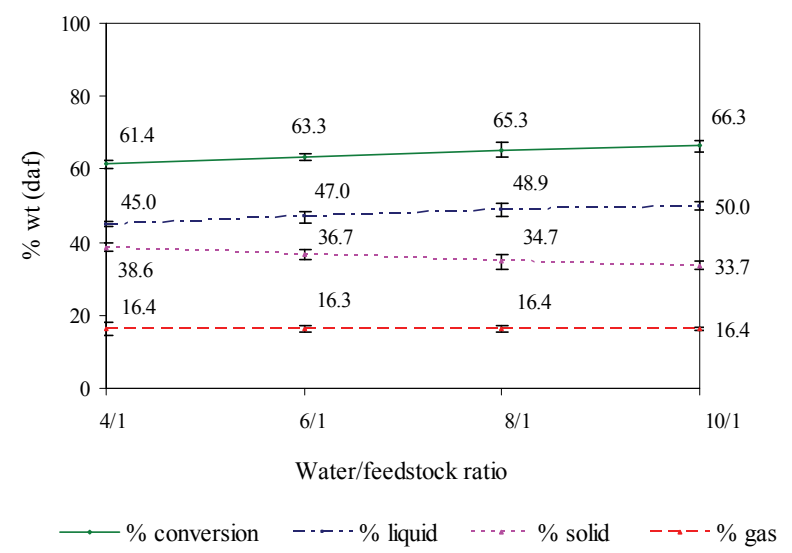

Figure 6. The effect of the water/feedstock ratio on the distribution of products from co-liquefaction of coal and used tire. (Reaction time $1 \mathrm{~min}$; temperature $400{ }^{\circ} \mathrm{C} ; 80 \%$ used tire content in feedstock). 


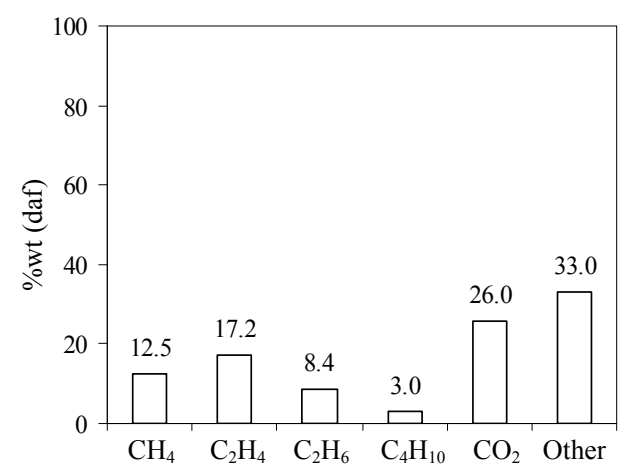

Figure 7. The effect of $\%$ used tire content in feedstock on the distribution of gas products obtained from their coliquefaction. (Reaction time $1 \mathrm{~min}$; temperature $400^{\circ} \mathrm{C}$; water/feedstock ratio of 10/1).

\subsection{The Effect of the \% Used Tire Content in Feedstock}

The effect of varying the amount of used tire content in feedstock on the product composition attained at $400^{\circ} \mathrm{C}$ with a water/feedstock ratio of $10 / 1$ and a reaction time of $1 \mathrm{~min}$ are summarized in Figure 8. The liquid yield attained was increased from 39.1 to $50.0 \%$ as the used tire content in feedstock was increased from 20 to $80 \mathrm{wt} . \%$. Because the depolymerization of used tires occurs easier than that for coal, likely due to the simpler structure of the tires, the thermal cracking of tire to form free radicals and water-gas shift reaction are stabilized by those produced during coal cracking. This results in a more efficient co-liquefaction process with coal and used tire relative to the liquefaction seen with only coal under the same conditions.

Moreover, these results show that adding used tire to the coal liquefaction process increases the total conver-

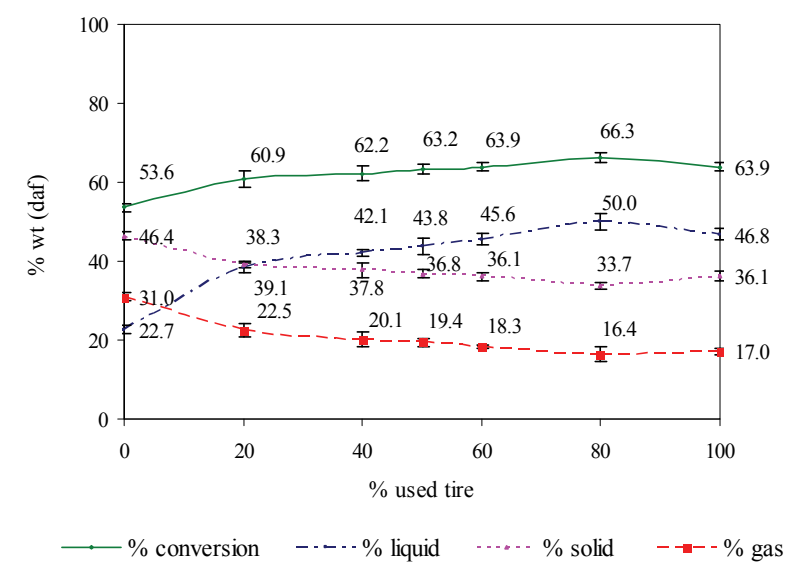

Figure 8. The effect of the $\%$ used tire content in feedstock on the distribution of products obtained from their co-liquefaction. (Reaction time $1 \mathrm{~min}$; temperature $400^{\circ} \mathrm{C}$; water/feedstock ratio of 10/1). sion of coal and the oil yield obtained. For example, the total conversion and oil yield obtained from using 80\% used tire content in feedstock were both synergistically higher than with only coal or tires alone under the same conditions.

\subsection{Analysis of the Liquid Products Obtained}

The liquid products obtained from the co-liquefaction were divided into gasoline, kerosene, light gas oil, gas oil and long residue by using Simulated Distillation Gas Chromatography (SIM/DIS GC). The effect of varying the reaction temperature, water/feedstock ratio and \% used tire content in feedstock on the oil product composition are summarized in Figure 9. The temperature and $\%$ used tire content in feedstock have a detectable effect upon the oil composition with the content of gasoline and kerosene being increased whilst long residues were decreased with both increasing temperature and $\%$ used tire content in feedstock. In contrast, the water/feedstock ratio had no discernable effect on the oil composition. The more severe thermolysis and depolymerization of the coal and used tire seen with increasing temperature and $\%$ used tire content in feedstock thus resulted in an increased yield of lighter and intermediate compounds at the expense of the higher MW compounds.

\subsection{The Effect of Catalysts}

The effect of using two established coal liquefaction catalysts, $2.5 \%\left(\mathrm{w} / \mathrm{w}\right.$ ) $\mathrm{Fe}_{2} \mathrm{O}_{3}$ and NiMo (Ni: $0.2 \mathrm{wt} \% \mathrm{db}$ coal, Mo: $0.6 \mathrm{wt} \% \mathrm{db}$ coal) particles, on the co-liquefaction of coal and tires was evaluated. Catalyst loading of the coal was prepared by an in situ impregnation method $[19,20]$. The co-liquefaction in SCW with or without catalysts was performed at $400^{\circ} \mathrm{C}$ for $1 \mathrm{~min}$, with a water/feedstock ratio of $10 / 1$, and $80 \%$ used tire content in feedstock.

The total conversion obtained in the presence of either of the two catalysts was almost equal to that obtained in their absence (Figure 10). However, the gas yield was increased significantly in the presence of either catalyst, with a concomitant reduction in oil yield. Thus, the catalysts perform further thermal cracking to give lighter liquid products. However, considering the absence in changes in total conversion, for solid to oil conversion (i.e. \% oil yield), it can be concluded that the process does not require either catalyst or additive.

\section{Conclusions}

In this work, the total conversion and liquid yield obtained from the co-liquefaction of coal and waste tire attained were 66 and 50\%, respectively, at the optimum reaction condition of $400^{\circ} \mathrm{C}$ for $1 \mathrm{~min}$, with wa- 


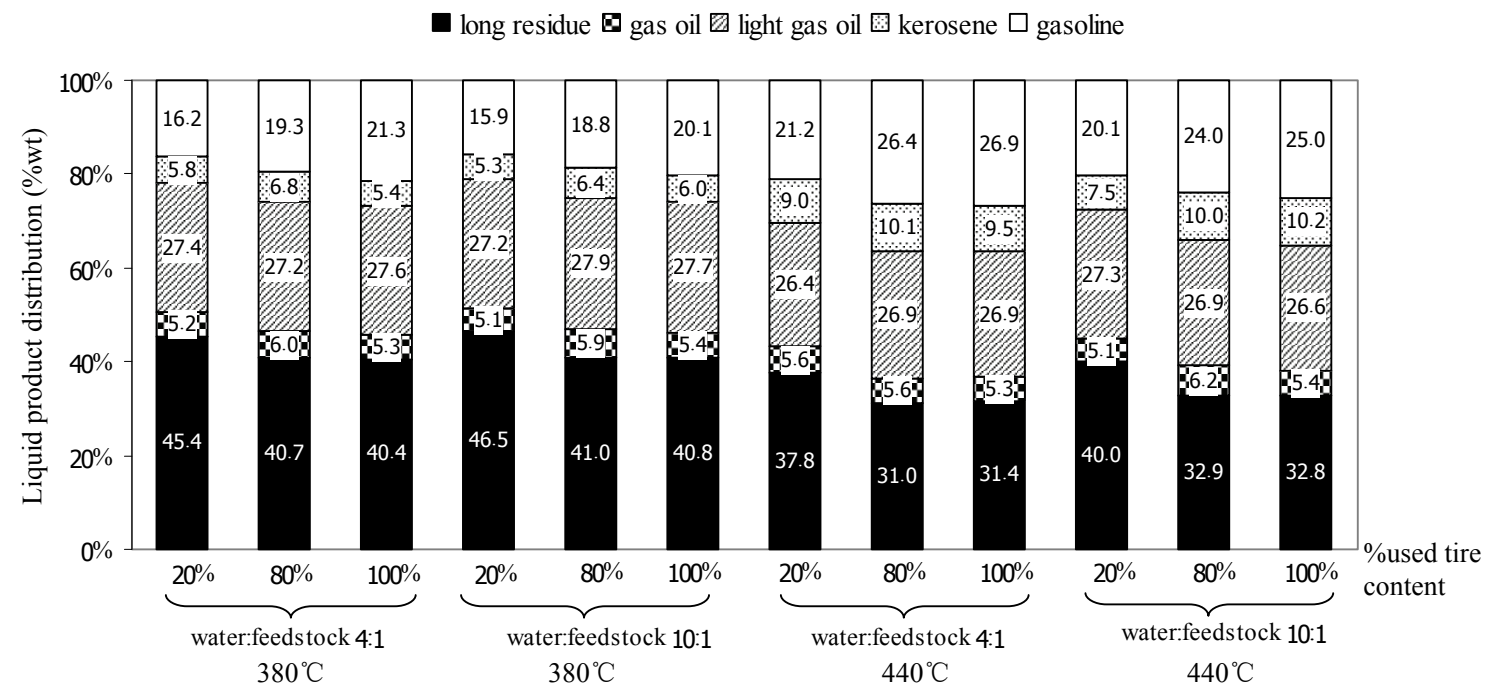

Figure 9. The effect of temperature, water/feedstock ratio, and \% used tire content in feedstock upon the composition of liquid products obtained from co-liquefaction.

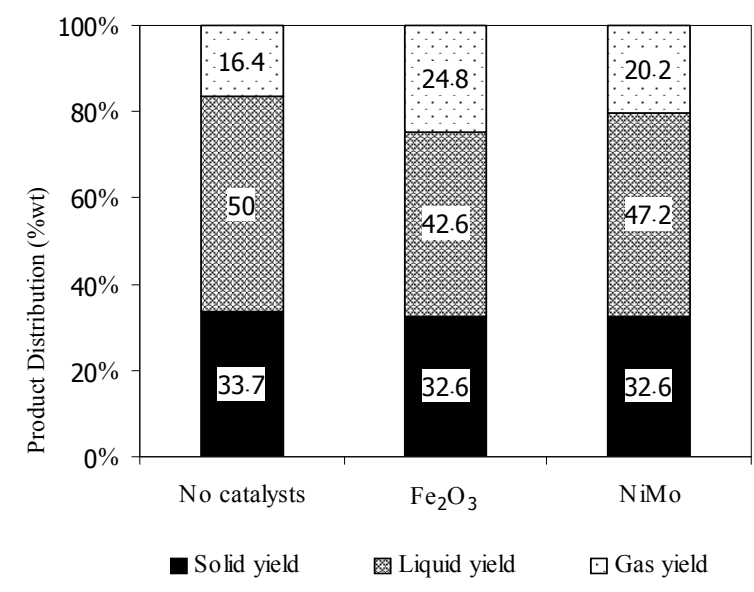

Figure 10. The effect of catalyst upon the distribution of products obtained from co-liquefaction of coal and used tire. The calculated total conversion (\%) is in parenthesis above each bar. $\left(400^{\circ} \mathrm{C}\right.$ for $1 \mathrm{~min}$, water/feedstock ratio of $10 / 1$, $80 \%$ used tire content in feedstock).

ter/feedstock ratio of $10 / 1$ and $80 \%$ used tire content. The total conversion increased with increasing temperature whilst liquid yields obtained increased with increasing temperature, water/feedstock ratio and \% used tire content in feedstock. Moreover, as reported in other systems, the addition of used tire to the coal co-liquefaction had a synergistic effect, whilst the key factor affecting the liquid product composition was temperature. SCW is a suitable medium to extract the volatile matter from waste tire, as a tire-coal matrix, without the need to use catalysts, long reaction times or organic solvents. Therefore, the co-liquefaction of coal and used tire in SCW is an attractive way for reducing waste tires by means of giving a moderate oil yield without the need for environmentally and economically costly long reaction times and chemical solvents, but rather provides rapid and easy separation of the oil product from all the other residual components.

\section{Acknowledgements}

This work was supported by Center for Petroleum, Petrochemicals and Advanced Materials and Graduate School, Chulalongkorn University.

\section{References}

[1] P. T. Williams and R. P. Bottrill, "Sulfur-Polycyclic Aromatic Hydrocarbons in Tyre Pyrolysis Oil," Fuel, Vol. 74, No. 5, 1995, pp. 736-742.

[2] G. C. Hwang, J. H. Choi, S. Y. Bae and K. Kumazawa, "Degradation of Polystyrene in Supercritical Hexane," Korean Journal of Chemical Engineering, Vol. 18, No. 6, 2001, pp. 854-861.

[3] S. N. Joung, S. W. Park, S. Y. Kim, K. P. You and S. Y. Bae, "Thermolysis of Scrap Tire Using Supercritical Toluene," Korean Journal of Chemical Engineering, Vol. 16, No. 5, 1999, pp. 602-607.

[4] A. V. Cugini, R. G. Lett and I. Wender, "Coal/Oil Coprocessing Mechanism Studies," Energy and Fuels, Vol. 3, No. 2, 1989, pp. 120-126.

[5] A. M. Mastral, R. Murillo, M. J. Perez-Surio and M. Callen, "Coal Hydrocoprocessing with Tires and Tire Components," Energy Fuels, Vol. 10, No. 4, 1996, pp. 941-947.

[6] Z. Liu, J. W. Zondolo and D. B. Dadyburjor, "Tire Liquefaction and its Effect on Coal Liquefaction," Energy 
Fuels, Vol. 8, No. 3, 1994, pp. 607-612.

[7] A. M. Mastral, R. Murillo, M. S. Callen and T. Garcia, "Evidence of Coal and Tire Interactions in Coal-Tire Coprocessing for Short Residence Times," Fuel Processing Technology, Vol. 69, 2000, pp. 127-140.

[8] M. Sugano, D. Onda and K. Mashimo, "Additive Effect of Waste Tire on the Hydrogenolysis Reaction of Coal Liquefaction Residue," Energy Fuels, Vol. 20, No. 6, 2006, pp. 2713-2716.

[9] Y. Tang and C. W. Curtis, "Thermal and Catalytic Coprocessing of Waste Tires with Coal," Fuel Processing Technology, Vol. 46, No. 3, 1995, pp. 195-215.

[10] T. Funazukuri, T. Takanashi and N. Wakoa, "Supercritical Extraction of Used Automotive Tire with Water," Journal of Chemical Engineering of Japan, Vol. 20, 1987, pp. 23-27.

[11] S. Park and E. F. Gloyna, "Statistical Study of the Liquefaction of Used Rubber Tyre in Supercritical Water," Fuel, Vol. 76, No. 11, 1997, pp. 999-1003.

[12] N. Akiya and P. E. Savage, "Roles of Water for Chemical Reactions in High-Temperature Water," Chemical Reviews, Vol. 102, No. 8, 2002, pp. 2725-2750.

[13] S. Sangon, S. Ratanavaraha, S. Ngamprasertsith and P. Prasassarakich, "Coal Liquefaction Using Supercritical Toluene-Tetralin Mixture in a Semi-Continuous Reactor," Fuel Processing Technology, Vol. 87, No. 3, 2006, pp. 201-207.
[14] X. Su, Y. Zhao, R. Zhang and J. Bi, "Investigation on Degradation of Polyethylene to Oils in Supercritical Water," Fuel Processing Technology, Vol. 85, No. 8-10, 2004, pp. 1249-1258.

[15] L. Cheng, R. Zhang and J. Bi, "Pyrolysis of a Low-Rank Coal in Sub- and Supercritical Water," Fuel Processing Technology, Vol. 85, No. 8-10, 2004, pp. 921-932.

[16] S. Sunphorka, P. Prasassarakich and S. Ngamprasertsith, "Co-liquefaction of Coal and Plastic Mixture in Supercritical Water," Journal of Scientific Research Chulalongkorn University, Vol. 32, No. 2, 2007, pp. 101-109.

[17] H. Hu, S. Guo and K. Hedden, "Xtraction of Lignin with Water in Sub- and Supercritical States," Fuel Processing Technology, Vol. 53, 1997, pp. 267-277.

[18] M. Watanabe, H. Hirakoso, S. Sawamoto, T. Adschiri and K. Arai, "Poly Ethylene Conversion in Supercritical Water," Journal of Supercritical Fluids, Vol. 13, No. 1-3, 1998, pp. 247-252.

[19] Y. Artanto, W. R. Jackson, P. J. Redlich and M. Marshall, "Liquefaction Studies of Some Indonesian Low Rank Coals," Fuel, Vol. 79, No. 11, 2000, pp. 1333-1340.

[20] Z. Liu, J. Yang, J. W. Zondlo, A. H. Stiller and D. B. Dadybujor, "In situ Impregnated Iron-Based Catalysts for Direct Coal Liquefaction,” Fuel, Vol. 75, No. 1, 1996, pp. 51-57. 